Case report

\title{
Selective bone marrow involvement of lymphoplasmacytic cells secreting monoclonal IgA rheumatoid factor in a patient with Sjögren's syndrome and serum hyperviscosity
}

\author{
C BERGONZI, ${ }^{1}$ G P MERLINI, ${ }^{2}$ S MORANDI, ${ }^{1}$ E BIANCHINI, \\ F PAVESI, ${ }^{2}$ V'BELLOTTI, ${ }^{2}$ C M MONTECUCCO, ${ }^{3}$ AND E ASCARI ${ }^{2}$ \\ From the ${ }^{1}$ Division of Medicine, Hospital of Cremona; the ${ }^{2}$ Institute of Clinical Medicine II and the ${ }^{3}$ Institute \\ of Medical Pathology 1, University of Pavia, Italy
}

SUMMARY The clinical features and results of serological studies of a patient with Sjögren's syndrome, IgA $x$ monoclonal gammopathy, and hyperviscosity syndrome are reported. The novel $\stackrel{\Phi}{\exists}$ aspect of this case is the selective localisation to the bone marrow of lymphoplasmacytoid cells secreting IgA $x$ morphologically identical to the cells infiltrating the salivary glands. The serum of the patient contained large amounts of immunoglobulin-anti-immunoglobulin immune con plexes. By gel filtration chromatography it was shown that the immune complexes formed a peack of molecular weight 680 kilodaltons. The immune complexes were dissociable under acidie conditions. The immunoglobulin with rheumatoid activity was characterised as monoclonal IgAx1 protein. Treatment with plasmapheresis combined with immunosuppressive treatment with cyclophosphamide reduced the serum viscosity with concomitant clinical improvement.

Key words: monoclonal gammopathy, collagen diseases, immune complexes, plasmapheresis, immunosuppressive treatment.

Sjögren's syndrome (SS) is a chronic, inflammatory, autoimmune exocrinopathy characterised by keratoconjunctivitis sicca, xerostomia (sicca complex), destructive infiltration of the lachrymal and salivary glands by lymphoid cells associated with the presence of autoantibodies. ${ }^{1}$

Lymphoid proliferation is a prominent feature of Sjögren's syndrome. ${ }^{2}$ A dynamic spectrum of lymphoproliferative lesions exists in SS, ranging from benign polyclonal lymphoplasmacellular infiltrates of the glandular tissue, to benign extraglandular lymphoproliferation ('pseudolymphoma'), 2 angioimmunoblastic lymphadenopathy with dysproteinaemia, ${ }^{34}$ and malignant lymphomas with monoclonal B cell characteristics, and dedifferentiated lymphomas with little or no immunoglobulin pro-

Accepted for publication 17 May 1987.

Correspondence to Dr C Bergonzi, Via Marmolada 16, 26100 Cremona, Italy. duction. ${ }^{2} 56$ Generally, the serum immunoglobulin pattern shows a polyclonal hypergammaglobulinaemia, though monoclonal immunoglobulins, predominantly IgM in non-Japanese patients, ${ }^{7} 3$ have been described sporadically in patients with $\mathrm{SS}^{89}$

We report the clinical features and the results of $\frac{D}{0}$ serological studies in a patient with SS associated with bone marrow involvement by lymphoplasmacy- $\sigma$ tic cells secreting a monoclonal IgA rheumatoid $N$ factor and hyperviscosity syndrome.

\section{Materials and methods}

Serum viscosity relative to distilled water was $\stackrel{\oplus}{\mathscr{C}}$ measured by an Ostwald capillary viscosimeter at $37^{\circ} \mathrm{C}$.

Electrophoresis and immunoelectrophoresis were $\stackrel{0}{\stackrel{0}{\circ}}$ performed in agarose gel (Miles Italiana $\mathrm{SpA}, \stackrel{\stackrel{\mathcal{D}}{\mathbb{Q}}}{\circ}$ 
Cavenago B, Milan, Italy) $0.75 \%(w / v)$ in $0.075 \mathrm{M}$ sodium barbital buffer, pH 8.6, with $0.002 \mathrm{M}$ calcium lactate. Goat monospecific antisera were purchased from Atlantic Antibodies (Scarborough, ME, USA). The absorbance at $280 \mathrm{~nm}$ was measured by means of a 2138 Uvicor spectrophotometer (LKB, Bromma, Sweden).

Gel filtration of the patient's serum was performed on AcA 22 (LKB) both in $0.1 \mathrm{M}$ TRIS-HCl, $0.5 \mathrm{M} \mathrm{NaCl}, \mathrm{pH} 7 \cdot 4$, and in dissociating buffer: 0.1 $M$ sodium acetate, $0 \cdot 15 \mathrm{M} \mathrm{NaCl}, \mathrm{pH} 4 \cdot 0$.

Affinity chromatography was performed as follows: IgG (10 g/l) was coupled to $\mathrm{CNBr}$ activated Sepharose 4B (Pharmacia Fine Chemicals, Uppsala, Sweden); $1 \mathrm{ml}$ of serum CAP was applied and the column washed with $0 \cdot 01 \mathrm{M}$ TRIS-HC1 buffer, $0 \cdot 15$ $\mathrm{M} \mathrm{NaCl}, \mathrm{pH} 7 \cdot 4$, and then eluted with $0 \cdot 1 \mathrm{M}$ glycine $\mathrm{HCl}$ dissociating buffer, $\mathrm{pH} 2 \cdot 5$. The eluted protein was dialysed at $4^{\circ} \mathrm{C}$ for 24 hours against $0.01 \mathrm{M}$ TRIS-HCl buffer, $0 \cdot 15 \mathrm{M} \mathrm{NaCl}, \mathrm{pH} 7 \cdot 4$, and then concentrated.

Goat monospecific human IgG antibody $(100 \mu \mathrm{l})$ was added to the eluted protein $(50 \mu \mathrm{l})$; this mixture was kept overnight at $4^{\circ} \mathrm{C}$, centrifuged, and the supernatant analysed by immunoelectrophoresis.

The anti-IgG (rheumatoid factor) activity of the isolated monoclonal component was evaluated with IgG coated latex particles (DENCO rheumatoid factor test, Carter-Wallace, Crenbury, NJ, USA).

The immunofluorescence studies were performed according to Hijmans $e t a l^{10}$; rabbit monospecific fluorescein isothiocyanate and tetramethylrhodamine isothiocyanate labelled antibodies were purchased from DAKO (DAKOPATTS, Copenhagen, Denmark).

Peripheral blood lymphocyte $\mathrm{T}$ subsets were detected by monoclonal antibodies (OKT series, Ortho, Immunologic Research Division, Raritan, NJ, USA).

\section{Case report}

A 64 year old woman had suffered for two years from dry mouth and conjunctivitis, purpuric spots on the lower part of the legs for six months, and from episodes of nose bleeding and blurred vision for one month before admission to hospital. Past medical history was irrelevant.

On admission the patient appeared pale and in very poor condition; she complained of headache and vertigo. Physical examination showed slight bilateral parotid enlargement, conjunctivitis, and purpura of the legs; there was neither hepatosplenomegaly nor lymphadenomegaly; funduscopic examination showed retinal haemorrhages and dilated veins; Schirmer's test disclosed decreased tear flow.
Laboratory studies showed an erythrocyte sedimentation rate (first hour) of $145 \mathrm{~mm}$, haemoglobin $75 \mathrm{~g} / \mathrm{l}$, white blood cell count $3 \cdot 5 \times 10^{9} / 1$, differential count: neutrophils $46 \%$, lymphocytes $38 \%$, monocytes $16 \%$, with marked rouleaux formation of the red cells, platelets $166 \times 10^{9} / 1$; blood urea nitrogen 16 $\mathrm{mmol} / \mathrm{l}$ (normal range (NR) 7-14); serum creatinine $88 \mu \mathrm{mol} / \mathrm{l}$ (NR 53-106); urine analysis showed traces of albumin and one or two erythrocytes/high power field. No Bence Jones protein was found. The total serum protein was $100 \mathrm{~g} / 1$, albumin $28.8 \mathrm{~g} / 1, \alpha_{1}$ globulins $3.2 \mathrm{~g} / \mathrm{l}, \alpha_{2}$ globulins $7.8 \mathrm{~g} / \mathrm{l}, \beta$ globulins fused with $\gamma$ globulins $60 \mathrm{~g} / \mathrm{l}$. The electrophoretogram showed the presence of a broad band in the $\beta-\gamma$ region.

Serum IgG and IgA were increased to $43 \mathrm{~g} / \mathrm{l}$ (NR 6-13) and $51 \mathrm{~g} / \mathrm{l}$ (NR 0.8-3) respectively, while IgM was $3 \cdot 2 \mathrm{~g} / 1$ (NR $0 \cdot 5-3 \cdot 6)$. Rheumatoid factor titre was $1 / 5120$. Serum complement levels $(C 3, C 4)$ were normal. The plasma viscosity was increased to 27.5 referred to $\mathrm{H}_{2} \mathrm{O}$ (NR 1.7-2.8). Coagulation tests were all normal. Tests for euglobulins (Sia test), pyroglobulins, cryoglobulins, and cold agglutinins were negative.

The bone marrow histological examination showed normal erythroid, granulocytic and megakaryocytic maturation; a prominent lymphoplasmacytic infiltration $(40 \%)$ without morphological abnormalities was noted. An immunofluorescence study showed intracellular IgA in $95 \%$ of lymphoplasmacytic cells positive for $x$ light chains.

Peripheral blood lymphocyte subtyping showed OKT3 83\% (NR 51-86), OKT4 71\% (NR 20-65),

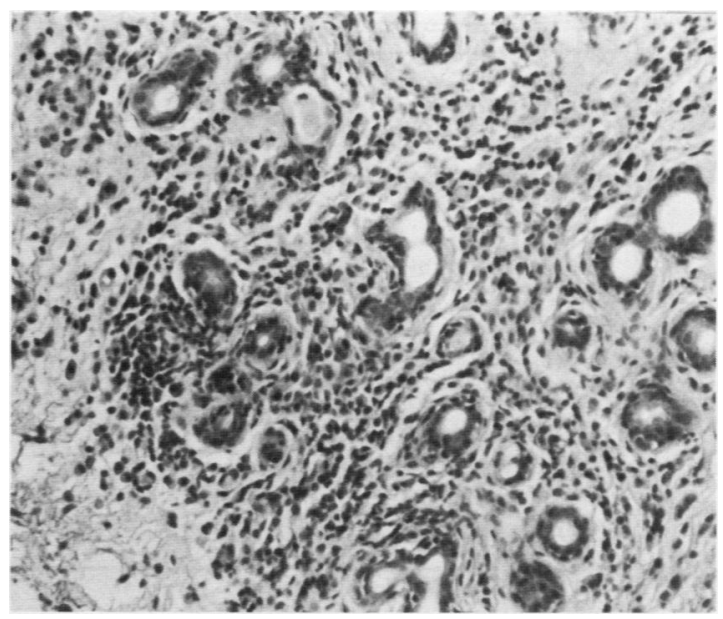

Fig. 1 Lip biopsy specimen: Prominent

lymphoplasmacytic infiltration and acinar atrophy are evident. (Haematoxylin and eosin.) 
OKT8 19\% (NR 12-38); the OKT4/OKT8 ratio was $3 \cdot 7$ (NR 1-2.4).

Skeletal $x$ rays showed no osteolytic lesions.

Tests for antinuclear antibodies, antimitochondrial, smooth muscle, cytoplasmic thyroid antigens, and gastric parietal cell antibodies were all negative. A lip biopsy showed acinar atrophy in the minor salivary glands with a conspicuous infiltration of lymphocytic and plasmacytic cells morphologically identical to the cells infiltrating the bone marrow (Fig. 1).

The patient was treated by plasmapheresis while serum viscosity, IgA, and IgG levels were monitored. A prompt clinical improvement of symptoms referrable to hyperviscosity was obtained. The need for frequent plasmapheresis to control hyperviscosity induced us to add immunosuppressive therapy with cyclophosphamide $(100 \mathrm{mg} / \mathrm{day})$. This therapy brought about a significant and persistent improvement in the patient's condition, without side effects, and with progressive decrease of $\operatorname{IgA} x$ level, rheumatoid factor titre, and serum viscosity, which has persisted.

\section{Results}

Serum was fractionated by gel filtration both in non-dissociating and dissociating conditions. In nondissociating conditions (Fig. 2A) the IgAs were eluted as a broad peak in the molecular weight range 850-320 kilodaltons, suggesting their involvement in the formation of the immune complexes. The rheumatoid factor activity precisely overlapped the elution profile of the IgAs. In acidic buffer the immune complexes dissociated, resulting in a narrowing of the elution peak of $\operatorname{IgA}$ around 160 kilodaltons. Also in this case the rheumatoid factor activity paralleled the elution profile of the IgAs.

Fig. 3 shows the agarose gel electrophoresis pattern of the patient's serum (Fig. 3a); a broad band is visible in the gamma-anodal region. The serum was passed through an IgG affinity column;

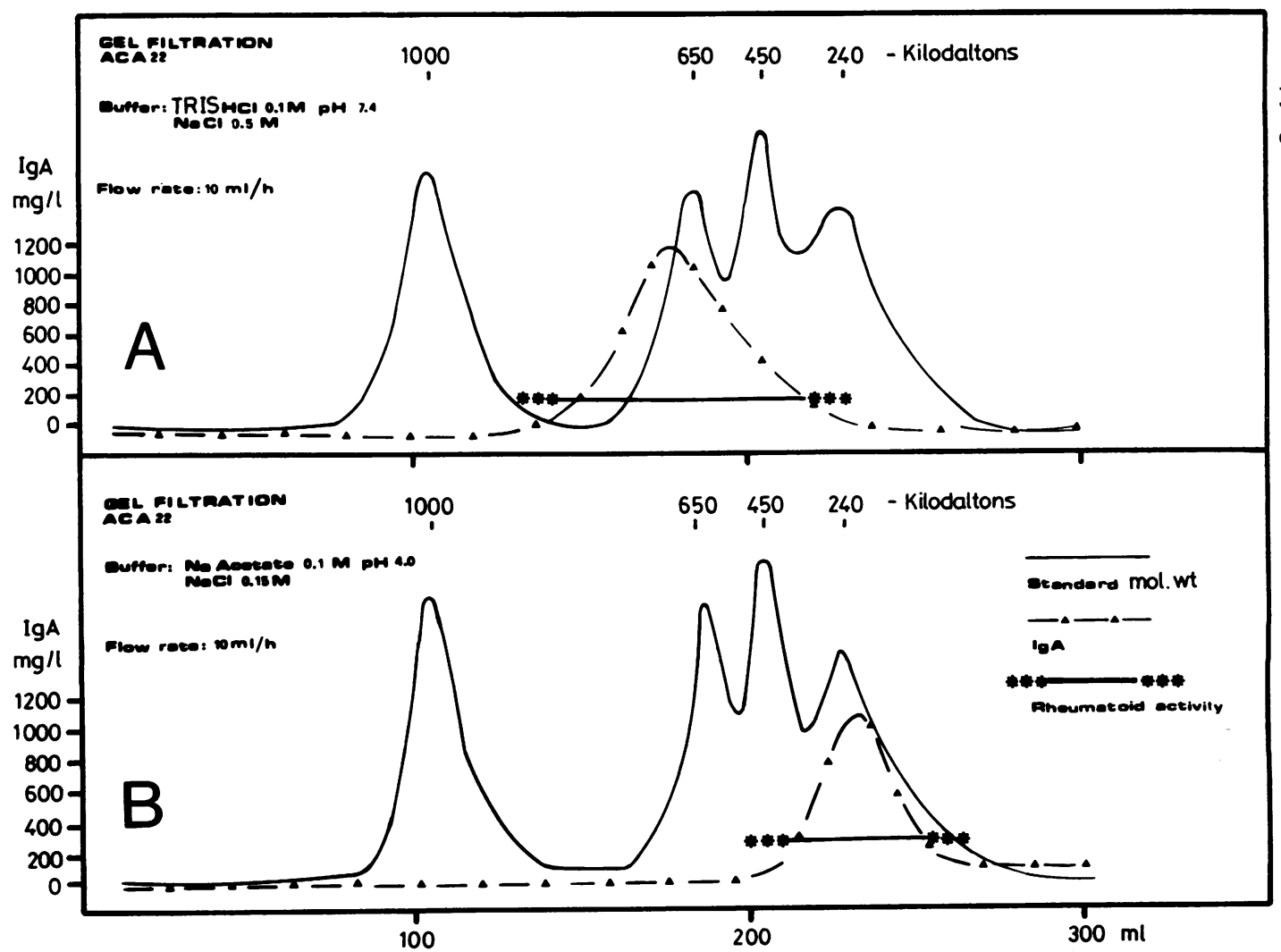

Fig. 2 (A) Gel filtration in non-dissociating buffer of the patient's serum. The elution pattern of IgA and rheumatoid factor activity are shown in comparison with molecular weight standards. (B) Gel filtration in dissociating buffer of the patient's serum: the shift of both IgA and rheumatoid factor activity toward a lower molecular weight is evident. 
the broad band was absorbed (Fig. 3b), and the serum lost all its rheumatoid factor activity. The IgG affinity column was washed exhaustively with phosphate buffered saline and then by acidic dissociating buffer: the resultant broad band was diluted 1:4 with respect to the starting serum and showed a rheumatoid factor titre of 1/1280 ( $v$ 1/5120 for the intact serum). These $\mathrm{M}$ bands of sera containing monoclonal rheumatoid factors (RFs) are broader on agarose gel than those usually seen in monoclonal gammopathies. The immunoelectrophoresis showed that this band comprised IgA $x$ and polyclonal IgGs. A sample of the fraction eluted from the IgG affinity column was mixed with anti-IgG antiserum, incubated at $4^{\circ} \mathrm{C}$ overnight, centrifuged, and the supernatant analysed by immunoelectrophoresis. The supernatant reacted with anti-IgA and anti- $x$ antisera, but not with anti-IgG. A faint $\lambda$ precipitin arc was seen; this was due to free $\lambda$ chains present in the goat anti-IgG antiserum. These results indicate that the material eluted from the IgG affinity column contained IgAx-polyclonal IgG immune complexes. The $x$ chain of the monoclonal $\operatorname{IgA}$ has been typed as $x 1$ by monospecific antisera (courtesy of $\mathrm{Dr}$

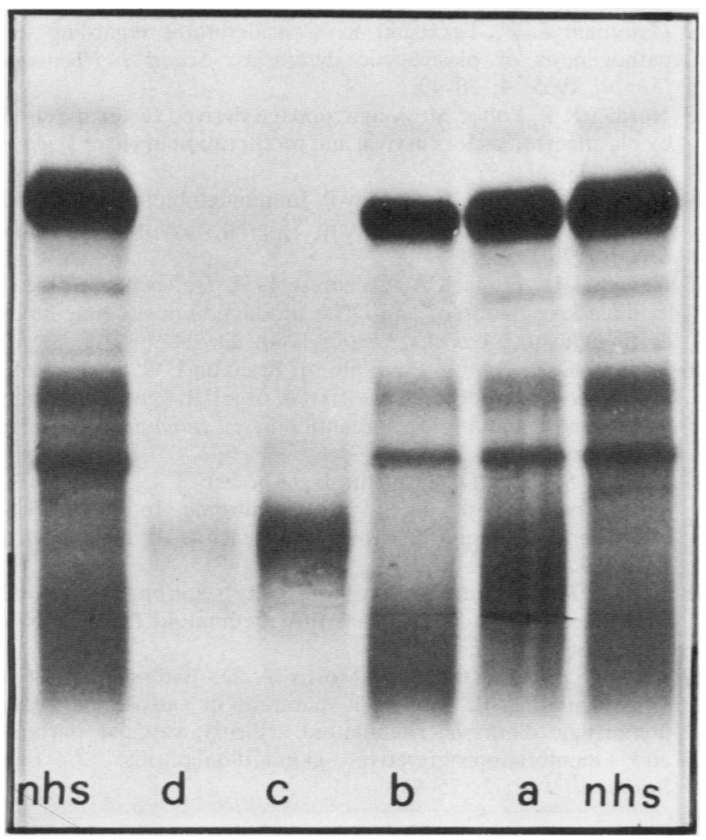

Fig. 3 Agarose gel electrophoresis: normal human serum (nhs), native serum of the patient (a); the patient's serum after absorption on IgG affinity column (b); protein eluted from the column by dissociating buffer (c); and diluted 1:10 in saline $(d)$.
A Solomon). The addition of goat monospecific human $\operatorname{IgG}$ antibody to the eluted protein left the monoclonal $\operatorname{IgA} x$ in solution. This observation could be explained by assuming that the binding affinity of IgAx for polyclonal IgG is quite low and that the anti-IgG antibody displaced the poly-IgG from the monoclonal IgA. Another possible explanation may be that only a fraction of the $\operatorname{IgAx}$ was engaged in the immune complex and precipitated by the anti-IgG antibody, leaving the unbound $\operatorname{IgA} x$ in solution.

\section{Discussion}

This case meets the current diagnostic criteria for SS. ${ }^{1}$ The association of SS with monoclonal gammopathies has been sporadically reported (for a review of the published work see Ref 9). In non-Japanese patients the monoclonal immunoglobulin is usually an IgM (74\%), whereas among Japanese patients IgA is the commonest (37\%). This association favours a role for chronic antigenic stimulation ${ }^{11}$ in the pathogenesis of monoclonal gammopathies. In SS the salivary gland is the site of chronic inflammation, triggered by an unknown mechanism, resulting in tissue destruction and exposure of cell antigens. Osserman and Takatsuki have pointed out that chronic inflammation may represent a stimulus for the in situ development of multiple myeloma. ${ }^{12}$ Nordan and Potter found that a macrophage derived factor supports the plasmacytoma growth in vitro and may therefore be involved in the neoplastic process of the establishment and maintenance of a plasmacytoma in vivo. ${ }^{13}$ IgA secreting cells are the main producers of immunoglobulins in the salivary glands and are directly exposed to the persistent stimulation which facilitates the transformation to monoclonal proliferation. The interesting occurrence of rheumatoid factors in SS has been recorded in a few patients. ${ }^{9}$ The autoimmune antigenantibody reaction which occurs in the salivary gland could stimulate the production of polyclonal rheumatoid factors in situ ${ }^{14}$ and chronic stimulation would then favour monoclonal rather than polyclonal rheumatoid factors.

Proliferation of B cells with production of autoantibodies can be greatly enhanced when suppressor $\mathrm{T}$ cells are deficient. ${ }^{15} \mathrm{~A}$ percentage reduction of suppressor T cells (OKT8) with an increase in the percentage of helper T cells (OKT4) was present in our patient. This $\mathrm{T}$ cell functional disregulation may contribute, together with the persistent antigenic stimulation, to the onset of a B cell clone secreting an immunoglobulin with autoantibody (rheumatoid factor) activity.

The novel aspect of this particular patient is the 
selective bone marrow infiltration $(40 \%)$ of monoclonal lymphoplasmacytoid $\operatorname{IgA} x$ positive cells without clinically evident involvement of other lymphoid organs (no hepatosplenomegaly or lymphadenomegaly). The production of $\operatorname{IgA}$ by lymphoplasmacytoid cells is rare as these cells usually produce IgM.

Although we do not have immunohistochemical data on the lymphoplasmacytoid cells infiltrating the salivary glands, these cells were morphologically identical to the cells infiltrating the bone marrow.

We propose that the same IgA secreting B cell clone present in the bone marrow also infiltrated the salivary glands, and cells in both sites contributed to the circulating monoclonal $\operatorname{IgA} x$. These findings contrast with those of Sugai et al, who presented evidence in two patients for $B$ cell proliferation and monoclonal immunoglobulin production $(\operatorname{IgA} x$ and $\operatorname{IgG} x)$ restricted to the salivary glands. ${ }^{7}$

The presence of $x$ light chains in the $\operatorname{IgA}$ protein with rheumatoid activity prompted us to check if they belonged to the xIIIb subgroup, which is notably related to rheumatoid activity. ${ }^{16}$ In this case, however, the $x$ chain belonged to subgroup I.

This patient presented features characteristic of the hyperviscosity syndrome: purpura, nose bleeds, headache, and vertigo associated with a marked increase of serum viscosity. A similar case of SS with monoclonal IgA with rheumatoid activity and hyperviscosity syndrome has been described by Sugai et al. ${ }^{7}$ It has been shown that the formation of monoclonal immunoglobulin-polyclonal IgG immune complexes with 'intermediate' coefficient sedimentation (13-14 S) can be responsible for serum hyperviscosity. ${ }^{17-19}$ In this case gel filtration studies of whole serum showed that the major portion of the immune complexes had a molecular weight of 680 kilodaltons. We also confirmed that the immune complexes were composed of monoclonal $\operatorname{IgA} x$ rheumatoid factor bound to polyclonal IgG. Temperature influences the solubility of serum immune complexes; it is noteworthy that in this serum cryoglobulins were absent. We ascribe the hyperviscosity to the configuration of the macromolecular IgA-IgG immune complexes in the patient's serum.

We are grateful to Professor N Talal, University of Texas, San Antonio, for reviewing the manuscript and to Ms Irene Zorzoli and Rosangela Cordani for skilful technical assistance.

\section{References}

1 Fox R I, Robinson C A, Curd J G, Cozin F, Howell F V. Sjögren's syndrome. Proposed criteria for classification. Arthritis Rheum 1986; 29: 577-85.

2 Anderson L G, Talal N. The spectrum of benign to malignant lymphoproliferation in Sjögren's syndrome. Clin Exp Immunol 1971; 9: 199-221.

3 Bignon Y J, Janin-Mercier A, Dubost J J, et al. Angioimmunoblastic lymphadenopathy with dysproteinaemia (AILD) and sicca syndrome. Ann Rheum Dis 1986; 45: 519-22.

4 Koo C H, Nathwani B N, Winberg C D, Hill L R, Rappaport H. Atypical lymphoplasmacytic and immunoblastic proliferation in lymph nodes of patients with autoimmune disease (autoimmune-disease-associated lymphadenopathy). Medicine (Baltimore) 1984; 63: 274-90.

5 Zulman $\mathrm{J}$, Jaffe $\mathrm{R}$, Talal $\mathrm{N}$. Evidence that the malignant lymphoma of Sjögren's syndrome is a monoclonal B-cell neoplasm. $N$ Engl J Med 1978; 299: 1215-20.

6 Talal N. Autoimmunity and lymphoid malignancy in New Zealand black mice. Prog Clin Immunol 1974; 2: 101-20.

7 Sugai S, Konda S, Shirasaki Y, Murayama T. Non-IgM monoclonal gammopathy in patients with Sjögren's syndrome. Am J Med 1980; 68: 861-6.

8 Bolognini G, Riva G. Lymphoproliferative Erkrankungen und Paraproteinamien beim Sjögren-Syndrom. Schweiz Med Wochenschr 1975; 105: 1493-505.

9 Sugai S, Shimizu S, Hirose Y, Takiguchi T, Konda S, Yamano $\mathrm{H}$. Monoclonal gammopathies in Japanese patients with Sjögren's syndrome. J Clin Immunol 1985; 5: 90-101.

10 Hijmans W, Schmit H R E, Klein F. An immunofluorescence procedure for the detection of intracellular immunoglobulins Clin Exp Immunol 1969; 4: 457-72.

11 Potter M. Myeloma proteins (M-components) with antibody like activity. $N$ Engl $J$ Med 1971; 284: 831-8.

12 Osserman E F, Takatsuki K. Considerations regarding the pathogenesis of plasmacytic dyscrasias. Scand J Haematol [Suppl] 1965; 4: 28-49.

13. Nordan R P, Potter M. A macrophage-derived factor required by plasmacytomas for survival and proliferation in vitro. Science 1986; 233: 566-9.

14 Talal N, Asofsky R, Lightbody P. Immunoglobulin synthesis by salivary gland lymphoid cells in Sjögren's syndrome. J Clin Invest 1970; 49: 49-54.

15 Clough J D, Frank S A, Calabrese L H. Deficiency of T-cell mediated regulation of anti-DNA production in systemic lupus erythematosus. Arthritis Rheum 1980; 23: 24-9.

16 Ledford D K, Goñi F, Pizzolato M, Franklin E C, Solomon A, Frangione B. Preferential association of $x$ IIIb light chains with monoclonal human IgM $x$ autoantibodies. J Immunol 1983; 131: $1322-5$.

17 Alarcon-Segovia D, Fishbein E, Abruzzo J L, Heimer R. Serum hyperviscosity in Sjögren's syndrome. Interaction between serum IgG and IgG rheumatoid factor. Ann Intern Med 1974; 80: 35-43.

18 Kosaka M, Solomon A. Hyperviscosity syndrome associated with an idiopathic monoclonal IgA-rheumatoid factor. Am J Med 1980; 69: 145-54.

19 Farhangi M, Luger A M, Morris A D. Pathogenesis of a monoclonal IgAk anti-IgG paraprotein associated with $\mathbb{O}$ hemorragic diathesis, rheumatoid arthritis, vascular purpura $N$ and membranoproliferative glomerulonephritis. $J$ Clin Immunol 1982; 2: 75-85. 